\title{
BIM for Building Water Supply and Drainage Design
}

\author{
Rong Yang, Wenwu Song
}

School of Energy and Power Engineering, Xihua University, Chengdu, 610039, China

Keywords: BIM, water supply and drainage design, application analysis.

\begin{abstract}
Building Information Modeling (BIM) application is increasingly popular across the globe, but not perfect in China. In order to improve BIM application level in building water supply and drainage design, this paper analyzed the application of BIM at home and abroad, and made recommendations for present problems combined with water systems design example. It points BIM will push the construction industry to a new comprehensive information age.
\end{abstract}

\section{Introduction}

With the advancement of economic development and human civilization, many varieties of fully functional and complex buildings become more. And building water supply and drainage design is an indispensable part of building engineering design. For now, water supply and drainage design in construction projects mainly includes water supply (drinking and fire water) design, drainage (rain, sewage, wastewater) design [1][2]. Fire water system typically includes sprinkler and hydrant systems [3]. For higher required buildings, they also include reclaimed water, central hot water supply and pipe portable water systems [4]. And in addition to water supply and drainage project design, construction design also includes a variety of professional design, such as HVAC, electric and other equipment [5]. From all of this, we can see its complexity. In order to make the design work better, a new concept and technology created-BIM. BIM was proposed in 2002 by Autodesk [6], and its emergence and development is another information innovation following CAD of the entire construction industry.

\section{The Concept and Development Status of BIM}

\section{BIM technology Concept}

BIM is short for Building Information Modeling. According to the National Building Information Modeling Standard definition, Building Information Modeling (BIM) is a digital representation of physical and functional characteristics of a facility. A BIM is a shared knowledge resource for information about a facility forming a reliable basis for decisions during its life-cycle; defined as existing from earliest conception to demolition [7]. In short, from planning and design to construction, operation and management of the entire life cycle of building, BIM plays a role in information sharing.

The technology of BIM mainly treats a basic component or a construction process in the construction project as a fundamental element. It forms a "Building Information Model" when we organize the data, physical and chemical properties associated with the basic elements as well as other relevant information together [8]. The model is a important data repository in a construction project. And this composed data not only reflects the basic characteristics of the building, but also have a definite link.

\section{The Development Status of BIM at Home and Abroad}

Currently in Europe, Japan and other developed areas, BIM technology use is more frequent. Especially in the construction sector in North America, the usage of BIM technology has been more than half, and at a faster pace. General Services Administration (GSA) in US requires all bidding items are required to apply BIM from 2007[9]. GSA is currently exploring BIM technology applications throughout the life cycle of projects, including spatial planning verification, 4D modeling, laser scanning, energy consumption and simulation of sustainable development, security verification and so on. In the UK, government mandatorily requires to use BIM. Government 
Construction Strategy mentioned, by 2016, the British government calls for a comprehensive collaborative 3D BIM, and all the documents need information management [10].

Recently BIM forms a craze in the domestic construction industry. Software vendors, government agencies, professional associations, design or construction units etc. pay attention and promote BIM gradually. Some colleges and universities have also joined the research and application of BIM, some of them have set up special BIM engineering master class [11]. In the industrial world, design institutes, construction units attempted for BIM in the early. For now, some large projects require the use of BIM in the whole life. Other projects will gradually write BIM into tender contract. The large or medium design enterprises basically have their professional team of BIM, construction companies started a little late, but all of them have some success stories and valuable experience. Overall, BIM in China need to be developed and will be at a faster pace, but still in the exploratory research stage at present.

\section{The Application of BIM in Water Supply and Drainage Design}

\section{Visualization}

In the previous two-dimensional design mode, designers mainly use traditional CAD platform, through using the ways of flat, vertical, cross-sectional view to show the content [12]. Building water systems design are independent, these systems also have an effect in several floors. In this operating mode, it is easy to result in fragmented and distorted three-dimensional information, and even cause errors during the process of information transmission, when encountering complex project or short construction period. But the intuitive and real-time features of BIM can ensure information's integrity and unity during transfer process. BIM designers can view the location of the device pipelines in three-dimensional model to judge rationality. Non-designers can also understand project information intuitively. This highly visual communication process is conducive to communicate and make decision.

\section{Synergy}

BIM will aggregate information into the model from various sectors; you can read the information across sectors [13]. When changes occur in other professional design, BIM software can intuitively get all dynamic, it saves a lot of time of communication and coordination.

\section{Materials Statistics}

In the past, water supply and drainage designers count materials according to the traditional method[14]. They measure in CAD and count manually. The work is over and complex, and it is easy to cause errors and waste time. The BIM repository contains this content-without manual work, it will be able to provide reliable real-time statistics of materials and provide effective information for engineering programs selection, final accounts and others.

\section{Integrated Pipeline}

BIM use the way of three-dimensional visual presentation to reflect all pipelines in space. Drainage designers can observe collision in the model when drawing to correct it, and also find errors through BIM collision detection. There is third-party software on market, which can detect hard and soft collision in models, such as Navisworks. In the BIM model, designers can not only find collisions within their field, but also detect the collision with others' fields, such as HVAC, electric, etc [15], thereby reducing the project work of modifications at post-construction.

\section{Construction Simulation}

In the traditional process of construction, they have to delay period because of space conflict among different professions. It often appears the situation that different designers refuse to compromise leading to require a longer time to coordinate.

The BIM started to introduce the concept of time; it can plan and schedule the various stages of construction scientifically and legitimately, evaluate rationality of design integrally and completely, coordinate installation jobs. It also reduces the waste of time, raises installation efficiency and achieves projects' pre-visualization. 


\section{BIM Application in Engineering Instance}

Below it takes example for designing a toilet's water systems to explain the main process of three-dimensional design and the main function of BIM.

\section{Installation of Sanitary Appliances}

In BIM design software, you can skip the traditional two-dimensional steps, directly use the families - washbasin, showers, etc - to set up a three-dimensional model of the building. It also can take advantage of two-dimensional plans. Two-dimensional CAD design plan needs to be import into 3D BIM software, then, determine the axis and elevation. Figure 1 is a plan view of the imported CAD. Designers choose sanitary equipments which meeting the relevant requirements from standard families. If its size and parameters do not meet the requirements, designers should change these families.

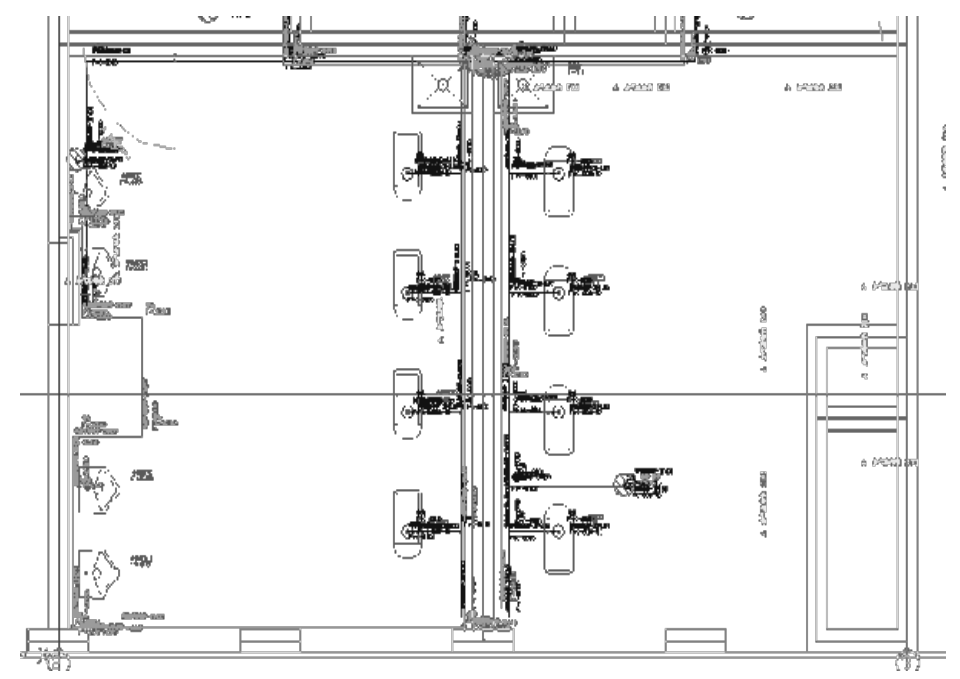

Fig.1: The imported CAD plan in BIM design software

\section{The Installment of Drainage Pipelines}

Toilet water supply and drainage system consists of horizontal tubes and standpipes. Designers need to set the basic parameters of the pipeline before connecting, including material, nominal diameter, installation height, slope, attachment type, etc. Then, install and draw pipelines at the corresponding position. After completing installation, they import it to the building structure model; take 3D model for visual rendering. You can observe the model clearly and intuitively. Figures 2 and 3 are finished 3D BIM renderings.

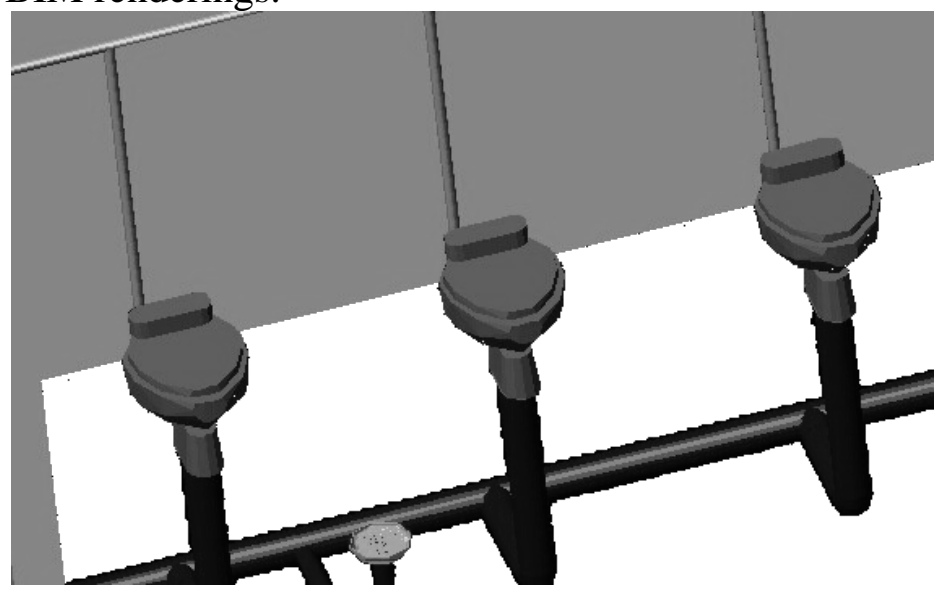

Fig.2: The toilet connected with water supply and drainage pipeline 


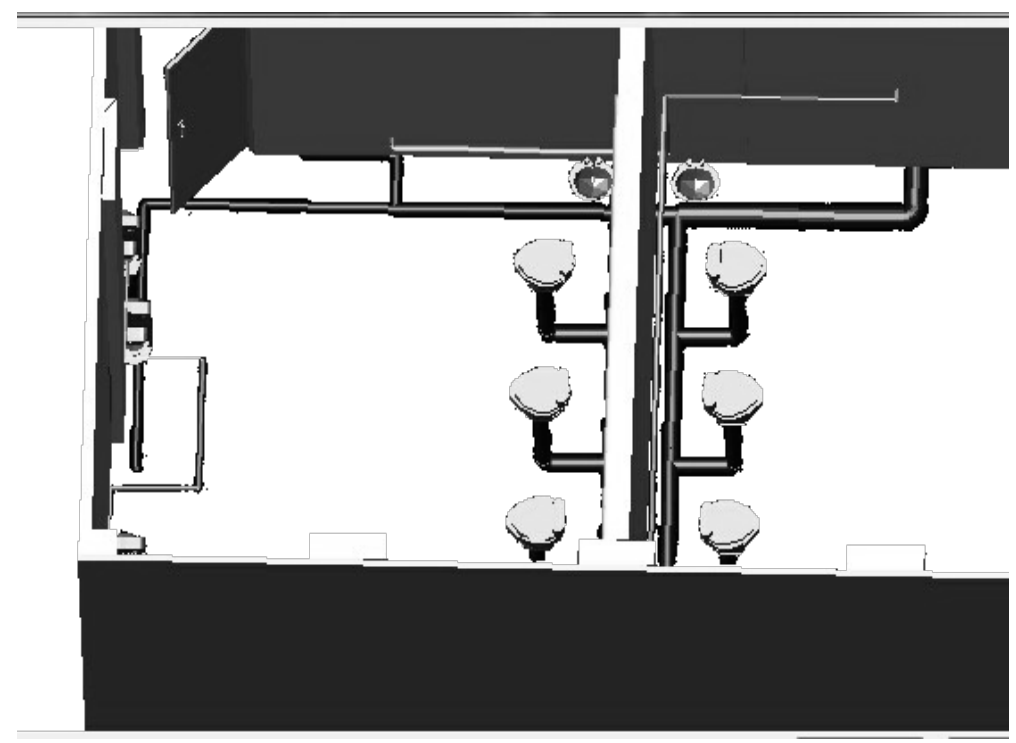

Fig.3: The BIM model of toilet

\section{The Pipeline Collision Detection}

In addition to manual check, BIM softwares - such as Autodesk Revit MEP-being used at present have the function of checking pipeline collision problems automatically. It greatly improves work's efficiency. Pipeline collision detection mainly works among drainage, HVAC, electric, structure and other equipment professions. After the collision check is completed, designers can look at the collision location by BIM and modify it, then detect errors again until collision does not appear. Figure 4 is a manual inspection of the pipelines collision with the designer's perspective in BIM modeling and figure 5 is automatic detection.

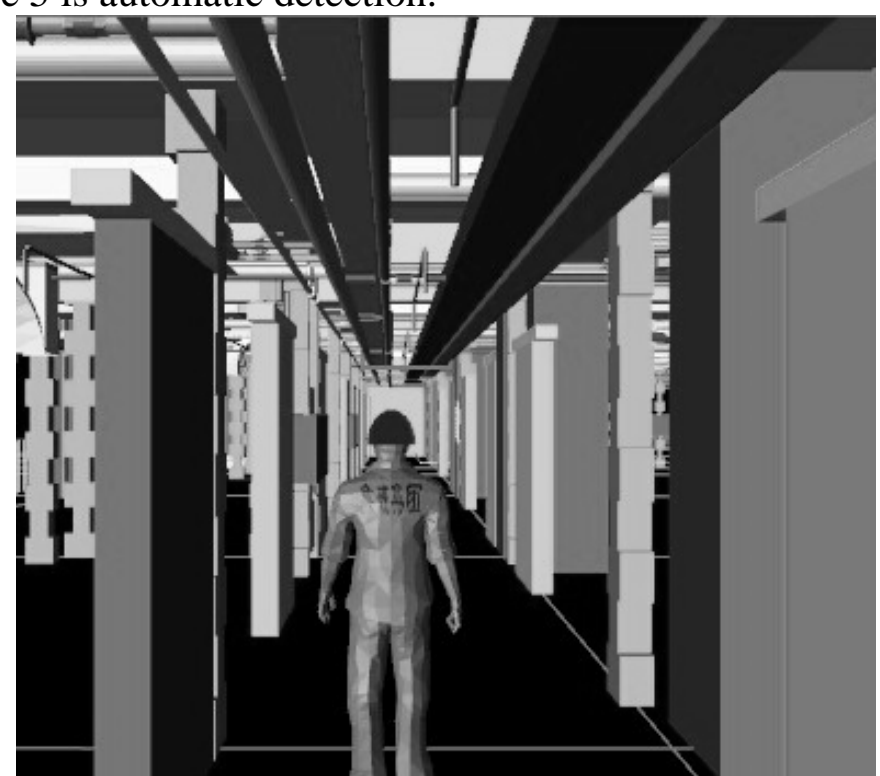

Fig.4: Manual inspection of pipelines collision in BIM 


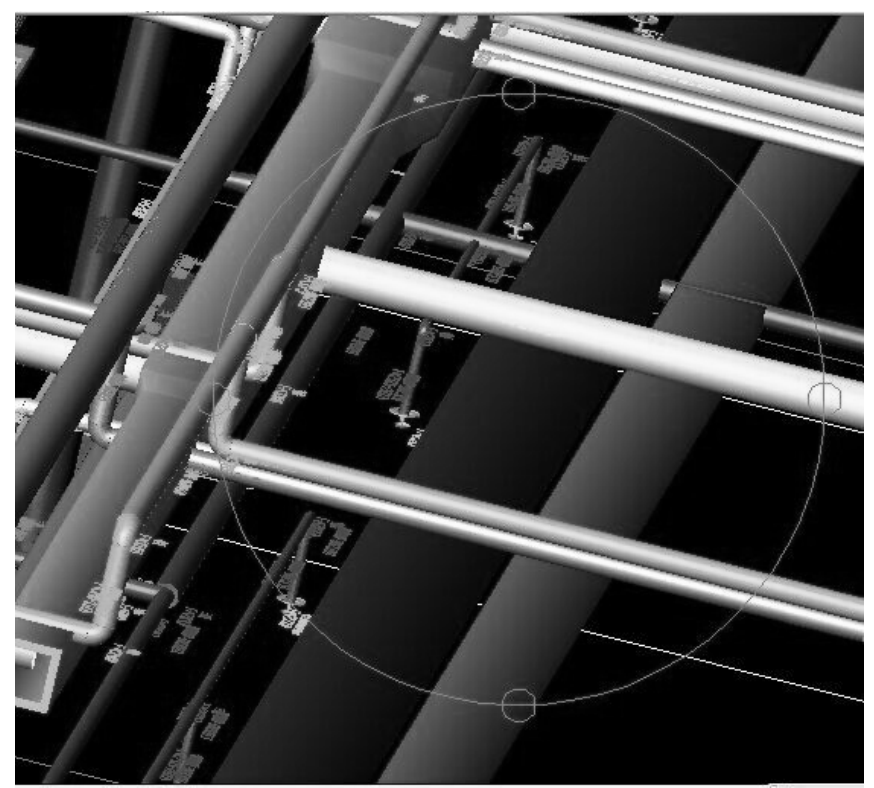

Fig.5: Automatic inspection of pipelines collision in BIM

\section{Conclusions}

The application of Building information modeling technology in Europe and other developed countries has a long time, their rules are more complete. But in China, it is still not long enough; the improvement of BIM which came from abroad is still insufficient. So BIM should be improved with Chinese national conditions specification to achieve localization as soon as possible. The standard component families in BIM software also need to be improved. In order to meet designers' requirements, software developers should exploit a better one according to the needs of designers. Although BIM has many imperfections, with the accelerated process of information construction, building information modeling technology represents the future's management and design direction, it will be gradually improved and mature. BIM has attracted the relevant state departments, design institutes, construction units and universities. Its spread career is well worth doing, and BIM technology will be popular in the designers as well as construction industry.

\section{Acknowledgements}

In this paper, the research was sponsored by the Nature Science Foundation of China (Project No. 51279172) and Graduate Innovation Fund of Xihua University (Project No. ycjj2014170).

\section{References}

[1] Zhang Z J. Drainage engineering [M]. China Architecture and Building Press, Beijing, 1999

[2] Yan X J, Fan J C. Water supply engineering [M]. China Architecture and Building Press, Beijing, 1999

[3] China Institute of Building Standard Design and Research: National technology measures for design of civil construction, 2009

[4] Wang Z C. Building water supply and drainage engineering [M]. China Architecture and Building Press, Beijing, 2005

[5] Liu X C. Using building information modeling to improve the mechanical, electrical and plumbing coordination[J]. Pioneering with Science and Technology, 2011,04:168-170

[6] Yang K, Kang D Z, Xu P, etc. BIM-based MEP design technology [J]. Construction Technology, 2014, 43(3):88-89

[7] National Institute of Building Science: United States National Building Information Modeling Standard, Version 1-Part 1, 2010. Information on http://buildingsmartalliance.org 
[8] Wu X T. Water supply and drainage system renovation and BIM technology application [J]. Construction and Design for Project, 2013,05:106-108

[9] General Services Administration(GSA) 3D-4D-BIM Program, information on www.gsa.gov/bim

[10] Cabinet Office, Government Construction Strategy, information on http://www.cabinetoffice.gov.uk/

[11] He L T, The application status of BIM in the world [J]. Construction Quality, 2013,03:12-19

[12] Qi B K, Li C F. Reserch on the whole lifecycle of prefabricated construction management based on BIM technology [J]. Construction Technology, 2013,43(15):25-29

[13] Gu H L, Gin T C. The application of BIM technology in Shanghai center building water supply and drainage design [J]. Water and Wastewater Engineering, 2012, 38(11):92-97

[14] Lu K X. Probe the application of BIM in building water supply and drainage design [J]. China Science and Technology Overview, 2012, 12:139-140

[15] Gao Y, Deng X Y. A study of BIM-based MEP technologies in building design [J]. Journal of Information Technology in Civil Engineering and Architecture, 2010, 2(2):91-96 